International Journal of

Environmental Research and

Public Health

ISSN 1660-4601

www.mdpi.com/journal/ijerph

Article

\title{
Maternal Smoking, GSTM1 and GSTT1 Polymorphism and Susceptibility to Adverse Pregnancy Outcomes
}

\author{
Regina Grazuleviciene $^{1{ }^{1} *}$, Asta Danileviciute ${ }^{1}$, Ruta Nadisauskiene ${ }^{2}$ and Jone Vencloviene ${ }^{1}$ \\ 1 Vytautas Magnus University, K. Donelaicio g. 58, LT-44248, Kaunas, Lithuania; \\ E-Mails: a.danileviciute@gmf.vdu.lt (A.D.); j.vencloviene@gmf.vdu.lt (J.V.) \\ 2 Kaunas University of Medicine, Eiveniu g. 2, LT-50009, Kaunas, Lithuania; \\ E-Mail: Ruta.nadisauskiene@kmuk.lt \\ * Author to whom correspondence should be addressed; E-Mail: r.grazuleviciene@gmf.vdu.lt; \\ Tel.: +370 650 27090; Fax: +37037 327904
}

Received: 4 February 2009 / Accepted: 21 March 2009 / Published: 26 March 2009

\begin{abstract}
The objective of the study was to investigate the association between maternal smoking, GSTM1, GSTT1 polymorphism, low birth weight (LBW, $<2,500 \mathrm{~g}$ ) and intrauterine growth restriction (IUGR, $<2,500 \mathrm{~g}$ and gestation $\geq 37$ weeks) risk. Within a prospective cohort study in Kaunas (Lithuania), a nested case-control study on LBW and IUGR occurrence among 646 women with genotyping of GSTT1 and GSTM1 polymorphisms who delivered live singletons was conducted. Multivariate logistic regression analysis was used to study the association of maternal smoking and polymorphism in two genes metabolizing xenobiotics. Without consideration of genotype, light-smoking (mean 4.8 cigarettes/day) during pregnancy was associated with a small increase in LBW risk, adjusted OR 1.21; 95\% CI $0.44-3.31$. The corresponding odds for IUGR risk was $1.57 ; 95 \%$ CI $0.45-5.55$. The findings suggested the greater LBW risk among light-smoking mothers with the GSTM1-null genotype (OR 1.91; 95\% CI 0.43 8.47) compared to those with GSTM1-present genotype (OR 1.11; 95\% CI 0.26 - 4.47). When both GSTM1 and GSTT1 genotypes were considered, the synergistic effect was found among smoking mothers: GSTT1-present and GSTM1-null genotype OR for LBW was 3.31 ; $95 \%$ CI $0.60-18.4$ and that for IUGR was 2.47 ; 95\% CI $0.31-13.1$. However there was no statistically significant interaction between maternal smoking, GSTT1present and GSTM1-null genotypes for LBW (OR 1.45; 95\% CI $0.22-10.1, \mathrm{p}=0.66$ ) and for IUGR (OR $1.10 ; 95 \%$ CI $0.10-12.6, p=0.93)$. The results of this study suggested that
\end{abstract}


smoking, even at a low-level, ought to be considered a potential risk factor for adverse birth outcomes and that genetic polymorphism may contribute to individual variation in tobacco smoke response.

Keywords: Tobacco smoking; GSTM1; GSTT1 polymorphism; low birth weight risk; fetal growth restriction.

\section{Introduction}

Tobacco smoking is known to be associated with adverse pregnancy outcomes. The root causes of many adverse pregnancy outcomes are not well understood, but there is growing evidence that the environment can play an important role. Environmental factors that may have such effects include tobacco smoking, socioeconomic disparities, ambient air pollution, and various other agents encountered both indoors and outdoors [1]. Recent epidemiologic studies have showed, that many adverse pregnancy outcomes might arise from the complex interactions between genes and environment as a function of the age- or stage of development of the individual $[2,3]$.

Active maternal smoking has been associated with a number of adverse reproductive outcomes [4]. Among them are the increased risk of low birth weight (LBW) [5-7], intra-uterine growth restriction (IUGR) [8,9], and, to lesser extent, preterm birth [10]. Numerous studies have found that infants born to smokers weigh substantially less than infants born to nonsmokers [11,12]. Even environmental tobacco smoke (ETS) has been shown to have a negative impact on birth weight. Among women who were exposed to ETS at home and work, infants were lower in weight at delivery in comparison with women who were never exposed to smoke, and even lower in weight when compared with women who smoked during pregnancy [6,7]. Consequently, ETS is recognized as a risk factor for reduction in birth weight and preterm birth of infants [10].

Tobacco smoke is a known to be toxic to humans. It contains over 3,000 chemicals of which over 200 are regarded as poisons and 50 as possible carcinogens [13]. It is generally accepted that there is no safe level of exposure to cigarette smoke [14]. Maternal smoking during pregnancy can result in both pregnancy complications and reduced size of the fetus and neonate. Among women who smoke, genetic susceptibility to tobacco smoke is also a likely causative factor in adverse pregnancy outcomes [15]. Smoking has an even stronger impact on birth weight than alcohol, and today maternal cigarette smoking has been identified as the single largest modifiable risk factor for IUGR in developed countries [16]. However, not all women who smoke cigarettes during pregnancy have LBW infants. The reason for this variability is largely unknown, but may be related to maternal genetic susceptibility [17].

Tobacco smoke is a complex mixture that contains, among other substances, polycyclic aromatic hydrocarbons (PAHs) and $N$-nitrosamines. Recent studies have shown that there are associations between exposure to PAHs and reduced fetal growth and preterm birth [1]. One study in the Czech Republic found that increasing PAH levels during the first month of pregnancy increased the risk of fetal growth restriction [9]. Both PAHs and $N$-nitrosamines are genotoxic and carcinogenic, and their metabolic activation leads to the formation of DNA adducts [15]. 
Several different classes of enzymes take part in the process of xenobiotic metabolism and carry out conjugation reactions such as the well-known glutathione $S$-transferases (GSTs) $[18,19]$. The GSTs are a polymorph super-gene family of detoxification enzymes that are involved in the metabolism of numerous toxins and provide critical defense against xenobiotics. GSTT1 encoded enzymes are involved in the metabolism and detoxification of PAHs [20-22]. The GSTT1 enzyme is also important in protecting against genotoxic damage, such as sister chromatid exchanges and the formation of hemoglobin adducts due to the ethylene oxide present in tobacco smoke [17]. GSTM1 enzyme encodes a major detoxification phase enzyme that helps detoxify various xenobiotics. Deficiency in GSTM1 activity is caused by homozygous deletion of GSTM1 and leads to various biological consequences [23]. Both GSTM1 - and GSTT1 enzymes exhibit genetic polymorphism (functional- and nonfunctional phenotypes), that have been shown to be related to birth weight of infants [24]. Several allelic variants of polymorphic GSTs show impaired enzyme activity and increase the risk of fetal development, as well as modify the effects of maternal smoking by increasing or decreasing its risk [25]. One of the maternal genetic polymorphisms of GSTM1 - and GSTT1 expression is through modification of oxidative stress caused by maternal exposure to tobacco smoke [26]. Therefore, the expression of different genotypes may lead to varying susceptibility to the adverse pregnancy effects of cigarette smoke.

In this study, we used a nested case-control design to examine the relationship between maternal smoking, the xenobiotic metabolizing gene GSTM1, GSTT1 polymorphism, and LBW, and fetal growth restriction risk. We hypothesized those women with the GSTM1 - and GSTT1 null genotype who are exposed to cigarette smoke during pregnancy are at elevated risk for adverse pregnancy outcomes.

\section{Methodology}

We conducted a prospective cohort study of pregnant women as a part of the European Commission FP6 HiWATE project [27]. This study, called the HiWATE cohort study, was carried out in the city of Kaunas. For genotype analysis, we used a nested case-control design to study the interactions of maternal smoking with GSTM1, GSTT1, and pregnancy outcomes in 646 women. The information on maternal smoking was obtained by means of a questionnaire.

On their first visit to a general practitioner, all pregnant women living in Kaunas between 2007 and 2008 were invited to join the cohort. We recruited these women for the prospective cohort study, enrolling them at first trimester of gestation at the four prenatal care clinics affiliated to the hospitals of the Kaunas University of Medicine. No compulsion of any kind was imposed on prospective participants for recruitment to the study. Participation was on a voluntary basis and the women were enrolled in the study only if they consented to participate in the cohort. We state that the study ethics comply with the Declaration of Helsinki. The research protocol was approved by the Lithuanian Bioethics Committee and oral informed consent was obtained from all subjects.

Pregnant women of the cohort were asked to answer two questionnaires provided to them at the clinic. The first questionnaire was designed to determine gestational age, maternal-, social, and demographic characteristics, diseases, and health behavior. All participants completed this questionnaire. In all, 3,005 pregnant women were registered of whom $63.9 \%$ were eligible and willing 
to be enrolled into the cohort. Women whose medical records indicated that they had pregnancyinduced hypertension, a history of diabetes mellitus or living outside the Kaunas municipality, were excluded from the study. A special questionnaire was evolved to interview the 1,919 women who agreed to participate; $76.4 \%$ of them were interviewed before delivery at hospital and blood samples for genetic analysis was collected. The interviews were conducted by a nurses experienced with this type of work. We also conducted telephone interviews to collect information from those women who agreed to participate in the study but were not interviewed before delivery. Telephone interviews of about $24 \%$ of the total enrolled women were completed within a first month after delivery.

Outcomes of interest related to LBW and fetal growth restriction. Pregnancy outcomes were ascertained primary from computerized hospital admission files as well as by abstraction of medical records. Birth weight was abstracted from the birth certificate for all newborns. The age of gestation was calculated using the data of birth as reported on the birth certificate and the $1^{\text {st }}$ day of the last menstrual period as was ascertained at first interview, and by ultrasound examination. We defined newborn weight less than $2,500 \mathrm{~g}$ as low birth weight and intra-uterine growth restriction as infants with birth weight less than $2,500 \mathrm{~g}$ for those newborns whose gestation period was 37 weeks or longer.

In this study "cases" were defined as women who delivered singleton, live, LBW infants (International Classification of Diseases ten revision (ICD-10), codes P07.0-07.1), or IUGR infants (ICD-10, codes P05.0 - 1; P05.9). Controls were defined as women who delivered singleton, live, term infants with birth weight $2,500 \mathrm{~g}$ or more.

The genotype analysis group included all women who delivered LBW or IUGR infants and who blood samples for genetic analysis was collected. Random ten controls were identified for every case. Multiple births or newborns with major births defects were excluded.

\subsection{Exposure Assessment}

The interview contained a number of variables including demographics (age, education, family status); reproductive history; job characteristics; self-reported psychosocial stress; health behavior; and diseases. We obtained information about tobacco use in the face-to-face and telephone interviews. We asked the women to report their daily cigarette consumption before pregnancy as well as during pregnancy. We defined "smokers" as those who smoked any number of cigarettes during pregnancy. We compared never smokers with women who smoked during pregnancy.

The self-reported stress of the respondents was assessed by the following thesis: my daily activities are very trying and stressful. Four respondent options were used to define stress: this describes my state (1) very well, (2) fairly well, (3) not very well, (4) not at all. Values 1 and 2 were considered to represent stress; 3 and 4 represented no stress.

The GSTM1- and GSTT1-null genotypes were identified by the multiplex polymerase chain reaction (PCR) in peripheral blood DNA samples. This method allows the detection of the presence of the genotype (at least 1 allele present: AA or Aa) or its absence (complete deletion of both alleles: aa).

Maternal blood samples were collected in vials containing EDTA and stored at a temperature of $-20^{\circ} \mathrm{C}$. DNA was purified from the peripheral blood using DNA purification kits (MBI "Fermentas", Vilnius, Lithuania). DNA concentrations were quantified with a spectrophotometer (Eppendorrf BioPhotometer, 61310488, Hamburg, Germany). A PCR-based study of GSTM1 and GSTT1 
polymorphism was carried out according to the method described previously [28]. The primers used for PCR were as follows:

GSTM1 forward 5'-GAA CTC CCT GAA AAG CTA AAG C-3'and reverse 5'-GTT GGG CTC AAA TAT ACG GTG G-3';

GSTT1 forward 5'-TTC CTT ACT GGT CCT CAC ATC TC-3' and reverse 5'-TCA CCG GAT CAT GGC CAG CA-3'.

As internal control, a 268-bp fragment of the human $\beta$-globin gene was coamplified with a second set of primers (5'-CAA CTT CAT CCA CGT TCA CC-3') and (5'-GAA GAG CCA AGG ACA GGT AC- 3') (Biomers.net - the Biopolymer factory, Germany). PCR was carried out in a final volume of $25 \mu \mathrm{l}$. The procedure followed for PCR was: primary denaturation at $94{ }^{\circ} \mathrm{C}$ for $5 \mathrm{~min}$, denaturation at $94{ }^{\circ} \mathrm{C}$ for $1 \mathrm{~min}$, annealing at $60{ }^{\circ} \mathrm{C}$ for $1 \mathrm{~min}$, extension at $72{ }^{\circ} \mathrm{C}$ for $1 \mathrm{~min}, 30$ cycles were conducted. Final extension was at $72{ }^{\circ} \mathrm{C}$ for $10 \mathrm{~min}$. The PCR products were electrophoresed in $2 \%$ agarose gels and stained in ethidium bromide. The DNA bands were visualised by UV transillumination (EASY Win32, Herolab, Germany). GSTM1 and GSTT1 polymorphisms were coded as present (GSTM1-1 and GSTT1-1) or absent (GSTM1-0 and GSTT1-0).

\subsection{Statistical Methods}

We evaluated tobacco smoke exposure in relation to birth outcomes by calculating crude- and adjusted odds ratios with their $95 \%$ confidence intervals $(95 \% \mathrm{CI})$ for the nested case-control sample. We used logistic regression models to estimate the individual and combined associations of maternal cigarette smoking and GSTM1 and GSTT1 genotypes in relation to newborn LBW and IUGR with adjustment for major covariates.

Comparisons of the associations between smoking and LBW risk factors were made by using Fisher's exact probability test [29]. In logistic regression models for LBW, we assessed a variety of potential confounders, identified from the literature and by univariate analysis. These included: maternal age, pre-pregnancy body mass index $\left(\mathrm{BMI}=\right.$ weight $/$ height $\left.^{2}\right)$ and blood pressure, parity and prior pregnancy history, diseases, education, marital status, employment status and hours worked, stress level, and alcoholic beverage consumption.

Using personal data of the nested case-control sample, we first examined the association between smoking and birth outcomes without consideration of genotypes. Further, we examined the combined association of maternal cigarette smoking and maternal genotypes with birth outcomes controlling for effect of major covariates that changed the adjusted odds ratio for smoking by $10 \%$ or more. The subgroups were defined for LBW and IUGR and by maternal smoking status during pregnancy (no vs yes) and genotype for GSTT1 (present vs absent) and GSTM1 (present vs absent). We used chi-square tests to examine the association between genetic polymorphisms and individual susceptibility to tobacco smoking. The gene-cigarette smoke interaction was also tested by adding a product term to the regression models. All the analyses were adjusted for following potential effect modifiers viz. maternal age, BMI, education, and marital status. 


\section{Results and Discussion}

\subsection{Results}

Among the pregnant women with smoking and pregnancy outcome data, $71.1 \%$ never smoked, $21.5 \%$ smoked before but not during pregnancy. Among the women who smoked during pregnancy, light smokers (mean 4.8 cigarettes/day) predominated (92.3\% of smokers) and only $7.7 \%$ of smokers smoked 10 or more cigarettes per day. In this cohort of women receiving prenatal care at a health maintenance organization, $5.0 \%$ of infants had LBW, 5.2\% were born preterm, and $2.0 \%$ were small for gestational age (intrauterine growth restriction, IUGR).

Table 1 presents maternal characteristics by tobacco smoke-exposure status. This is the overall lowrisk population, with the majority of women at their optimal reproductive ages, high education, most having the ideal BMI, blood pressure, and most non-smokers. Smoking during pregnancy was associated with maternal age, education, marital status, and smoking history before pregnancy: the $\mathrm{P}$ value of exact test was $p<0.05$. Infants of active smokers revealed non-significant reduction in mean birth weight: among non-smokers, the birth weight was $3445 \pm 25 \mathrm{~g}$, and light smokers $-3365 \pm 59$, $\mathrm{p}=0.2$.

Table 1. Percent distribution of subjects by smoking for various characteristic and pregnancy outcomes.

\begin{tabular}{|c|c|c|c|c|}
\hline \multirow{2}{*}{$\begin{array}{l}\text { Maternal characteristics } \\
\text { Variables }\end{array}$} & \multirow{2}{*}{$\begin{array}{l}\text { Total } \\
\mathbf{N}\end{array}$} & \multicolumn{2}{|c|}{ Smoking during pregnancy $(\%)$} & \multirow{2}{*}{$\begin{array}{l}\text { Exact test } \\
p\end{array}$} \\
\hline & & None & Yes & \\
\hline \multicolumn{5}{|l|}{ Age: } \\
\hline$\leq 20 y$ & 28 & 71.4 & 28.6 & \\
\hline $21-30 y$ & 402 & 86.8 & 13.2 & \\
\hline$>30 \mathrm{y}$ & 216 & 92.1 & 7.9 & 0.004 \\
\hline \multicolumn{5}{|l|}{ Education: } \\
\hline college and $\leq 12 \mathrm{y}$ & 337 & 79.8 & 20.2 & $<0.001$ \\
\hline \multicolumn{5}{|l|}{ Marital status: } \\
\hline married & 493 & 92.3 & 7.7 & \\
\hline not married & 153 & 73.9 & 26.1 & $<0.001$ \\
\hline \multicolumn{5}{|l|}{ Parity: } \\
\hline $1^{\text {st }}$ & 320 & 89.1 & 10.9 & \\
\hline $2^{\text {rd }}$ and more & 326 & 86.8 & 13.2 & 0.38 \\
\hline \multicolumn{5}{|l|}{ Pregnancy history: } \\
\hline no prior & 517 & 87.2 & 12.8 & \\
\hline losses & 129 & 90.7 & 9.3 & 0.28 \\
\hline
\end{tabular}


Table 1. Cont.

\begin{tabular}{|c|c|c|c|c|}
\hline \multicolumn{5}{|l|}{ Gestational age: } \\
\hline$\geq 37$ weeks & 600 & 87.5 & 12.5 & \\
\hline$<37$ weeks & 46 & 93.5 & 6.5 & 0.23 \\
\hline \multicolumn{5}{|l|}{ Blood pressure: } \\
\hline$\leq 140-90 \mathrm{~mm} / \mathrm{Hg}$ & 558 & 87.8 & 12.2 & \\
\hline$>140 / 90 \mathrm{~mm} / \mathrm{Hg}$ & 88 & 88.6 & 11.4 & 0.83 \\
\hline \multicolumn{5}{|l|}{ Stress: } \\
\hline no & 523 & 88.5 & 11.5 & \\
\hline yes & 123 & 85.4 & 14.6 & 0.33 \\
\hline \multicolumn{5}{|l|}{ Mother diseases: } \\
\hline no & 474 & 88.8 & 11.2 & 0.25 \\
\hline yes & 172 & 85.5 & 14.5 & \\
\hline \multicolumn{5}{|l|}{ Body mass index (BMI): } \\
\hline normal - overweight $(25.1-30)$ & 558 & 87.8 & 12.2 & 0.83 \\
\hline obesity $(>30)$ & 88 & 88.6 & 11.4 & \\
\hline \multicolumn{5}{|l|}{ Smoking before pregnancy: } \\
\hline none & 461 & 100.0 & 0.0 & \\
\hline $1-9$ cigs. $/ \mathrm{d}$ & 169 & 60.4 & 39.6 & \\
\hline$>9$ cigs. $/ \mathrm{d}$ & 16 & 31.3 & 68.8 & $<0.001$ \\
\hline \multicolumn{5}{|l|}{ Smoking duration before pregnancy: } \\
\hline non smoker & 461 & 100.0 & 0.0 & \\
\hline $1-5 y$ & 122 & 66.4 & 33.6 & \\
\hline $6-10 y$ & 47 & 44.7 & 55.3 & \\
\hline$>10 y$ & 16 & 31.3 & 68.7 & $<0.001$ \\
\hline Mean birth weight $(\mathrm{g}), \pm \mathrm{SD}$ & $3,436 \pm 24$ & $3,445 \pm 25$ & $3,365 \pm 59$ & 0.21 \\
\hline
\end{tabular}

Table 2 presents variables that were associated with maternal smoking and other known LBW risk factors and provides inferential statistics, that is, odds ratios and 95 percent confidence intervals for the discrete variables. In univariate analyses, increasing number of cigarettes smoked was associated with an increased risk in LBW infants. Smokers of 9 cigarettes and more per day had crude odds ratios 1.97 (95\% CI 0.78-5.02) times those of unexposed women; however, a small number of LBW cases were reported among smokers and that had an effect on the statistical significance of the results. Age, marital status and blood pressure had statistically significant effect on LBW risk. These risk factors were incorporated into multivariate logistic regression models. Variables that were associated with IUGR risk were same as LBW.

Table 2. Distribution of maternal characteristics among low birth weight (LBW) cases and controls, odds ratios (OR) and their 95\% confidence intervals (CI).

\begin{tabular}{lcccccc}
\hline \multirow{2}{*}{ Maternal characteristics } & \multicolumn{2}{c}{ Cases LBW } & \multicolumn{2}{c}{ Controls } & \multicolumn{2}{c}{ Inferential statistics } \\
& $\mathbf{N}$ & $\mathbf{\%}$ & $\mathbf{N}$ & $\mathbf{\%}$ & OR & $\mathbf{9 5 \%}$ CI \\
\hline Age: & & & & & & \\
$21-30 \mathrm{y}$ & 26 & 45.6 & 376 & 63.8 & 1 & \\
$\leq 20 \mathrm{y}$ & 5 & 8.8 & 23 & 3.9 & 3.14 & $1.11-8.94$ \\
$>30 \mathrm{y}$ & 26 & 45.6 & 190 & 32.3 & 1.98 & $1.12-3.50$ \\
\hline
\end{tabular}


Table 2. Cont.

\begin{tabular}{|c|c|c|c|c|c|c|}
\hline \multicolumn{7}{|l|}{ Education: } \\
\hline college $\&<12$ y & 29 & 50.9 & 308 & 52.3 & 0.95 & $0.55-1.63$ \\
\hline \multicolumn{7}{|l|}{ Marital status: } \\
\hline married & 37 & 64.9 & 456 & 77.4 & 1 & \\
\hline not married & 20 & 36.1 & 133 & 22.6 & 1.85 & $1.04-3.30$ \\
\hline \multicolumn{7}{|l|}{ Parity: } \\
\hline $1^{\text {st }}$ & 26 & 45.6 & 294 & 49.9 & 1 & \\
\hline $2^{\text {nd }}$ and more & 31 & 54.4 & 295 & 50.1 & 1.19 & $0.69-2.05$ \\
\hline \multicolumn{7}{|l|}{ Previous pregnancy history: } \\
\hline no prior & 42 & 73.7 & 475 & 80.6 & 1 & \\
\hline losses & 15 & 26.3 & 114 & 19.4 & 1.49 & $0.80-2.78$ \\
\hline \multicolumn{7}{|l|}{ Blood pressure: } \\
\hline$\leq 120 / 80-140-90 \mathrm{~mm} / \mathrm{Hg}$ & 52 & 91.2 & 506 & 85.9 & 1 & \\
\hline$>140 / 90 \mathrm{~mm} / \mathrm{Hg}$ & 5 & 8.8 & 83 & 14.1 & 0.59 & $0.23-1.51$ \\
\hline \multicolumn{7}{|l|}{ Stress: } \\
\hline no & 45 & 78.9 & 478 & 81.2 & 1 & \\
\hline yes & 12 & 21.1 & 111 & 18.8 & 1.15 & $0.59-2.24$ \\
\hline \multicolumn{7}{|l|}{ Mother diseases: } \\
\hline no & 41 & 71.9 & 433 & 73.5 & 1 & \\
\hline yes & 16 & 28.1 & 156 & 16.5 & 1.08 & $0.59-1.99$ \\
\hline \multicolumn{7}{|l|}{ Body mass index (BMI): } \\
\hline $\mathrm{BMI}>30$ & 7 & 12.3 & 135 & 22.9 & 1 & \\
\hline $\mathrm{BMI} \leq 30$ & 50 & 87.7 & 454 & 77.1 & 2.12 & $0.94-4.79$ \\
\hline \multicolumn{7}{|l|}{ Smoking during pregnancy: } \\
\hline non smoker & 39 & 68.4 & 422 & 71.6 & 1 & \\
\hline$\leq 9$ cig. & 17 & 29.8 & 152 & 25.8 & 0.87 & $0.45-1.68$ \\
\hline$>9$ cig. & 1 & 1.8 & 15 & 2.5 & 1.97 & $0.78-5.02$ \\
\hline
\end{tabular}

In terms of GSTT1 and GSTM1 genotype frequency, women in the group exposed to tobacco smoke and the groups not exposed were similar. Table 3 presents the combined association of maternal cigarette smoking and maternal genotypes with LBW controlling for effect of major covariates.

The percentage of GSTT1 absent genotype was $16.9 \%$ and that of GSTM1 was $46.6 \%$. As shown in Table 3, without consideration of genotype, maternal smoking during pregnancy was associated with an adjusted OR of 1.21 (95\% CI $0.44-3.31)$ for LBW compared with the non - smokers. When GSTT1 genotype was considered, the association between maternal smoking and LBW increased and the adjusted OR was 2.06 (95\% CI 0.67 - 6.37) among mothers with genotype present, but we could not assess the association among mothers with absent genotype because of 0 LBW cases in the smokers group.

When GSTM1 genotypes were considered, the association between maternal smoking and LBW differed: the adjusted OR was $1.11(95 \%$ CI 0.26 - 4.76) among mothers with present but adjusted OR was 1.91 (95\% CI 0.43-8.47) among mothers with absent genotypes. However, a test of interaction between smoking and the GSTM1 - null genotype showed that there was no statistically significant evidence for an effect modification adjusted OR 1.54; 95\% CI $0.25-9.91, p=0.59$. Presence of both 
GSTT1 and GSTM1 genotypes tended to increase the smoking effect by 1.49 , while the GSTT1 present genotype and GSTM1 - null genotype were associated with 3.31 times higher risk among smokers (OR 3.31 95\% CI 0.60-18.4). A test of interaction between maternal smoking and two studied genotypes did not confer a significant adverse effect on LBW risk, adjusted OR 1.45; 95\% CI 0.22 $10.1, \mathrm{p}=0.66$.

Table 3. Crude and adjusted associations as odds ratios (OR) maternal smoking during pregnancy with low birth weight by maternal genotypes.

\begin{tabular}{lllllc}
\hline Genotype & $\begin{array}{l}\text { Smoking } \\
\text { status }\end{array}$ & $\mathbf{N}$ & $\begin{array}{l}\text { LBW, } \\
\text { \% }\end{array}$ & $\begin{array}{c}\text { Crude } \\
\text { OR 95\% CI }\end{array}$ & $\begin{array}{c}\text { Adjusted* } \\
\text { OR 95\% CI }\end{array}$ \\
\hline Total sample & Never & 342 & 8.8 & & \\
& Quitter & 86 & 10.5 & $1.220 .55-2.67$ & $1.180 .53-2.62$ \\
& Smoking & 52 & 11.5 & $1.360 .54-3.44$ & $1.210 .44-3.31$ \\
\hline GSTT1 & Never & 289 & 9.0 & & \\
Present & Smoking & 38 & 15.8 & $1.900 .73-4.96$ & $2.060 .67-6.37$ \\
GSTT1 & Never & 53 & 7.5 & & \\
Absent & Smoking & 14 & 0 & & \\
\hline GSTM1 & Never & 168 & 8.9 & & \\
Present & Smoking & 31 & 9.7 & $1.090 .30-4.0$ & $1.110 .26-4.76$ \\
GSTM1 & Never & 174 & 8.6 & & \\
Absent & Smoking & 21 & 14.3 & $1.770 .47-6.69$ & $1.910 .43-8.47$ \\
\hline
\end{tabular}

** Interaction: smoking x GSTM1 OR $1.62(0.25-10.4), \mathrm{p}=0.60 ; \mathrm{OR}^{*} 1.54(0.25-9.91), \mathrm{p}=$ absent 0.59

\begin{tabular}{llllll}
\hline GSTT1 \& GSTM1 & Never & 145 & 9.7 & & \\
Present & Smoking & 22 & 13.6 & $1.480 .39-5.62$ & $1.490 .33-6.79$ \\
GSTT1 present \& & Never & 144 & 8.3 & & \\
GSTM1 absent & Smoking & 16 & 18.8 & $2.540 .63-10.2$ & $3.310 .60-18.4$ \\
\hline
\end{tabular}

**Interaction: smoking x GSTT1 OR $1.72(0.25-11.8), \mathrm{p}=0.58$; OR* $1.45(0.22-10.1), \mathrm{p}=$ present \& GSTM1 absent $\quad 0.66$

*Logistic regression model: women $\mathrm{BMI} \leq 30$, age $\geq 20$ years, adjustment for maternal education and marital status.

**Test of interaction: a $\mathrm{P}$ value is presented for testing the null hypothesis, odds ratio $=1.0$ in logistic regression models for the product term, smoking x genotypes.

Table 4 presents the combined association of maternal smoking and GSTT1 - and GSTM1 genotypes with IUGR. Without considering genotypes, maternal smoking during pregnancy was associated with an adjusted OR of 1.57 (95\% CI 0.45-5.55) for IURG compared with the non smokers. 
Table 4. Crude and adjusted associations as odds ratios (OR) maternal smoking during pregnancy with intrauterine fetal growth restriction by maternal genotypes.

\begin{tabular}{lllllc}
\hline Genotype & $\begin{array}{l}\text { Smoking } \\
\text { status }\end{array}$ & $\mathbf{N}$ & $\begin{array}{l}\text { LBW, } \\
\mathbf{\%}\end{array}$ & $\begin{array}{c}\text { Crude } \\
\text { OR 95\% CI }\end{array}$ & $\begin{array}{c}\text { Adjusted* } \\
\text { OR 95\% CI }\end{array}$ \\
\hline Total sample & Never & 325 & 4.0 & & \\
& Quitter & 80 & 3.8 & $0.940 .26-2.36$ & $0.850 .23-3.10$ \\
& Smoking & 50 & 8.0 & $2.090 .65-6.68$ & $1.570 .45-5.55$ \\
\hline GSTT1 & Never & 274 & 4.0 & & \\
Present & Smoking & 36 & 11.1 & $2.990 .90-9.94$ & $2.630 .65-10.6$ \\
GSTT1 & Never & 51 & 3.9 & & \\
Absent & Smoking & 14 & 0 & & \\
\hline GSTM1 & Never & 158 & 3.2 & & \\
Present & Smoking & 30 & 6.7 & $2.190 .40-11.8$ & $2.000 .30-13.2$ \\
GSTM1 & Never & 167 & 4.8 & & \\
Absent & Smoking & 20 & 10.0 & $2.210 .44-11.2$ & $1.700 .28-10.4$ \\
\hline ***nteraction: smoking & x GSTM1 & OR $1.01(0.10-10.5), \mathrm{p}=0.99 ;$ OR* $0.98(0.09-10.3), \mathrm{p}=0.99$ \\
absent & & & & & \\
\hline GSTT1 \& GSTM1 & Never & 136 & 3.7 & & \\
Present & Smoking & 21 & 9.5 & $2.760 .50-15.2$ & $2.660 .38-18.5$ \\
GSTT1 present \& & Never & 138 & 4.3 & & \\
GSTM1 absent & Smoking & 15 & 13.3 & $3.390 .62-18.5$ & $2.470 .31-13.1$ \\
\hline
\end{tabular}

** Interaction: smoking x GSTT1 OR $1.23(0.11-13.7), \mathrm{p}=0.87$; OR* $1.10(0.10-12.6), \mathrm{p}=0.93$ present \& GSTM1 absent

*Logistic regression model: women BMI $\leq 30$, age $\geq 20$ years, adjustment for maternal education and marital status. **Test of interaction: a $\mathrm{P}$ value is presented for testing the null hypothesis, odds ratio $=1.0$ in logistic regression models for the product term, smoking $\mathrm{x}$ genotypes.

When we considered genotype GSTT1, the association between tobacco smoke exposure and IURG tended to be higher, and adjusted OR was found to be 2.63 (95\% CI $0.65-10.6)$ among the mothers group with GSTT1 genotype present. The estimated smoking effect tendered to be higher among mothers with the GSTM1 - null allele, compared with non-smoking mothers OR was 1.70 (95\% CI 0.28 - 10.4). We found some evidence of synergistic effect the GSTT1 and GSTM1 genotypes and active maternal smoking: OR were 2.66 (95\% CI $0.38-18.5)$ for both alleles present and OR 2.47 (95\% CI 0.31 - 13.1) for GSTM1 absent; nevertheless, there was no statistically significant interaction, adjusted OR 1.10; 95\% CI $0.10-12.61, \mathrm{p}=0.93$.

\subsection{Discussion}

In this molecular epidemiological study on maternal cigarette smoking and genetic determinants of xenobiotic metabolism, we found some evidence that effects of maternal smoking on LBW risk and infant growth were increased by maternal GSTM1 null genotype. This study used a case-control 
design to analyze the genetic effects and the gene-environment interaction controlling for major confounding variables. Consistent with previous studies, we found that maternal cigarette smoking was associated with fetal growth restriction and increased risk of LBW risk [5,17]. Our findings are consistent with a number of other studies that LBW risk may vary in relation to maternal age, BMI, parity, and other variables of the population in the study [29-31]. Some other investigators who have examined the issue, revealed dose-response gradients in relation to the amount smoked [4,33].

Present our findings show the greater LBW risk among light-smoking mothers with GSTM1 null genotype compared to those with GSTM1 present genotype, however the findings do not show a statistically significant results. These results are consistent with previous studies which analysed genetic susceptibility to cigarette smoke in the context of LBW or IUGR risk.

Wang et al. reported that pregnant women with certain genotypes are susceptible to the adverse pregnancy effects of tobacco smoking, such as an increased risk of LBW [17]. Without consideration of genotype, maternal smoking during pregnancy was associated with reduction in birth weight and elevated risk of LBW. When GSTT1 genotype was considered, the reduction in birth weight increased and $1.7(0.9-3.2)$ - fold elevated risk of LBW for those with the genotype present, and $3.5(1.5-8.3)$ - fold elevated risk of LBW for GSTT1 genotype absent was found among smoking mothers. The corresponding features for IUGR were $3.3(1.7-6.3)$ and $2.5(0.9-6.4)$, suggesting an interaction between metabolic genes and maternal smoking.

It has been reported that an individual difference in metabolic activation and detoxification xenobiotics partly depends on the genetic polymorphisms associated with GSTT1 and GSTM1 enzymes [33]. The interactive effect of exposure to tobacco smoke and the presence of the GSTT1 polymorphism on infant birth weight was found to be significant by multivariate analysis, whereas the interactive effect of the presence the GSTM1 polymorphism did not reach statistical significance $(\mathrm{p}=0.21)[25]$.

Sasaki et al. also reported combined effects between maternal genetic polymorphisms and smoking during pregnancy [35]. The effects on reduction birth weight were not observed among women with GSTM1 null genotype who had never smoked. The authors conclude that maternal smoking in combination with maternal genetic susceptibility may adversely affect infant birth weight. However, results presented here do not show a statistically significant association between infant birth size and maternal smoking as linked to the GSTT1 genotype, while birth weight and length were significantly lower in subjects with GSTM1 null genotype.

Sram et al. found that the risk of LBW and prematurity was significantly increased by the genotypes of GSTM1 null and a genotype combination with the CYP1A1*2A genotype [36]. A survey among pregnant women have shoved that a combination of the GSTM1 null and the GSTT1 null genotypes exacerbate the effect of maternal exposure to tobacco smoke on birth weight more than the presence of either genotype one [24].

Different results were presented by some authors [25]. In the case-control study, controlling for several confounding factors, the authors revealed that the maternal GSTT1 null genotype had a 1.6 fold reduced risk for small-for-gestational-age births. However, after adjustment for maternal smoking (categories less than 10 cigarettes/day and more than 10 cigarettes/day) the results were not statistically significant. 
There is evidence that effect of cigarette smoke exposure depends on population characteristics: among Japanese GSTM1 null genotype decreases fetal growth but this effect is not observed in Caucasians. Moreover, the adverse effect on birth weight did not always accompany fetal growth restriction [37].

Previous studies have suggested several plausible gene-smoking interaction explanations. First, tobacco smoke could disturb fetal and placental cellular regulation via elevated PAH-DNA adducts due to the increased activity of enzymes that metabolize cigarette toxins (e.g. CYP1A1) and lower or absent activity of enzymes that detoxify these compounds (e.g. GSTT1 and GSTM1 null genotypes) [15]. Second, gene-smoking interactions may exert their synergistic effects through oxidative stress that occurs upon tobacco smoke exposure. In response to this stress various inflammatory cytokines are produced in lung tissue increasing inflammatory responses and immune responses [38]. Moreover, as reported by some authors, maternal exposure to tobacco smoke affects the fetal urine cotinine concentration and also induces production of oxidative stress [26]. Further, other environmental factors and genetic polymorphism of GSTM1 and GSTT1 may modify the response to oxidative stress and lead to adverse pregnancy outcomes [32].

In this study, we demonstrated that there is increase in LBW and IUGR risk among smoking women even after adjusting for maternal age, education, BMI, and marital status; however, these findings suggest that there was no significant association between the GSTT1 and GSTTM1 polymorphism with low-level maternal smoking during pregnancy. The reason may be that the size of our nested case-control study and the proportion of women who smoked during pregnancy were too small to detect any significant difference.

Consistent to previous studies, we found that the effect of tobacco smoke increased LBW risk in the women's group with combination of GSTT1 present and GSTM1 absent alleles was more than 3 times greater compared with the non-smokers group (OR 3.31; 95\% CI 0.6 - 18.4). Similar evidence of the synergic effect of GSTT1 and GSTM1 polymorphism we revealed on fetal growth restriction, adjusted OR 2.47; 95\% CI 0.31 - 13.1. The adverse effects of GSTM1 null genotype on IUGR in the presence of cigarette smoke exposure were observed even among light smokers. These data strengthen the previous research findings that indicated that subjects with GSTM1 null genotype have a greater risk of toxic tobacco smoke effects while restricted fetal growth among light smokers provides evidence of unhealthy development in uterus [35].

When the results of this study are interpreted, a few conditions should be taken into account. This is a low-risk population with low-level tobacco smoke exposure, and low prevalence of GSTT1 null genotypes and these factors may limit extrapolation of these results to the other populations. The evaluation of exposure to tobacco smoke was indirect; we used self-reported information on smoking during- and before pregnancy, and thus the possibility of reporting bias exists. Because of the subjective measure of smoking exposure, there is a possibility of random exposure classification errors. However, in this study, we controlled for the main variables that might confound the association between smoking, genetic polymorphism, and birth outcomes, among them age, BMI, education, and family status, therefore, the residual confounding of results by smoking is expected to be small.

Our findings stress the need for appropriate policy and programs aimed at cessation of tobacco use among pregnant women. The evidence of increased risk of adverse birth outcomes in presence of 
genetic polymorphism reinforces the motivation argument for quitting smoking. This could help in directing smoking cessation interventions toward pregnant women and prevent adverse birth outcomes since smoking prevalence rate and effectiveness of tobacco control programs mostly depend not only on legislative recourses, but also on the individual perceiving that smoking is harmful to health $[39,40]$.

\section{Conclusions}

In summary, we have demonstrated that tobacco smoke exposure, even at a low-level, is associated with fetal growth restriction. Such as association, however, is modified by an individual's genotype. This study supports the importance of considering genetic susceptibility in prevention of adverse birth outcomes and evaluation of the effectiveness of anti-smoking preventive programs.

\section{Acknowledgements}

This work was supported in part by grant FP6-036224 from the European Commission. We acknowledge the contribution of the Clinics of Kaunas University of Medicine involved in registration of pregnancy outcomes.

\section{References and Notes}

1. Stillerman, K.P.; Mattison, D.R.; Giudice, L.C.; Woodruff, T.J. Environmental exposures and adverse pregnancy outcomes: a review of the science. Reprod. Sci. 2008, 15, 631-650.

2. Ramos, R.G.; Olen, K. Gene-environment interactions in the development of complex disease phenotypes. Int. J. Environ. Res. Public Health 2008, 5, 4-11.

3. Edwards, T.M.; Myers, J.P. Environmental exposures and gene regulation in disease etiology. Environ. Health Perspect. 2007, 115, 1264-1270.

4. Windham, G.C.; Hopkins, B.; Fenster, L.; Swan, S.H. Prenatal active or passive tobacco smoke exposure and the risk of preterm delivery or low birth weight. Epidemiology 2000, 11, 427-433.

5. Pollack, H.; Lantz, P.M.; Frohna, J.G. Maternal smoking and adverse birth outcomes among singletons and twins. Am. J. Public Health 2000, 90, 395-400.

6. Hruba, D.; Kachlik, P. Influence of maternal active and passive smoking during pregnancy on birthweight in newborns. Cent. Eur. J. Public Health 2000, 8, 249-252.

7. Tierney-Gumaer, R.; Reifsnider, E. Risk factors for low birth weight infants of Hispanic, African American, and white women in Bexar county, Texas. Pub. Health Nurs. 2008, 25, 390-400.

8. Kramer, M.S. Intrauterine growth and gestational duration determinants. Pediatrics 1987, 80, 502-511.

9. Dejmek, J.; Solansky, I.; Benes, I.; Lenicek, J.; Sram, R.J. The impact of polycyclic aromatic hydrocarbons and fine particles on pregnancy outcome. Environ. Health Perspect. 2000, 108, 1159-1164.

10. California Environmental Protection Agency. Proposed identification of environmental tobacco smoke as a toxic air contaminant: Part B health effects; California Environmental Protection 
Agency: Sacramento, CA, USA, 2005; Available online: http://repositories.cdlib.org/context/tc/ article/1194/type/pdf/viewcontent/ (accessed on September 14, 2008).

11. Office of the Surgeon General. Women and smoking: a report of the Surgeon General; Department of Health and Human Services: Washington, DC, USA, 2001; Available online: http://www.cdc.gov/tobacco/data_statistics/sgr/sgr_2001/sgr_women_chapters.htm (accessed on September 14, 2008).

12. Wilcox, A.J. Birth weight and perinatal mortality: the effect of maternal smoking. Am. J. Epidemiol. 1993, 137, 1098-1104.

13. IARC (International Agency for Research on Cancer). Tobacco smoking and involuntary smoking; ARC Monographs on the Evaluation of Carcinogenic Risks to Humans; IARC: Lyon, France, 2004; Vol. 83; Available online: http://monographs.iarc.fr/ENG/Monographs/vol83/index.php (accessed on September 14, 2008).

14. Zhu, B.Q.; Heeschen, C.; Sievers, R.E.; Karliner, J.S.; Parmley, W.W.; Glantz, S.A.; Cooke, J.P. Second hand smoke stimulates tumor angiogenesis and growth. Cancer Cell 2003, 4, 191-196.

15. Sasaki, S.; Sata, F.; Katoh, S.; Saijo, Y.; Nakajima, S.; Washino, N. Konishi. K.; Ban, S.; Ishizuka, M.; Kishi, R. Adverse birth outcomes associated with maternal smoking and polymorphisms in the N-nitrosamine-metabolizing enzyme genes NQO1 and CYP2E1. Am. J. Epidemiol. 2008, 167, 719-726.

16. Bada, H.S.; Das, A.; Bauer, C.R.; Shankaran, S.; Lester, B.M.; Gard, C.C. Wright, L.L.; Lagasse, L.; Higgins, R. Low birth weight and preterm births: Etiologic fraction attributable to prenatal drug exposure. J. Perinatol. 2005, 25, 631-637.

17. Wang, X.; Zuckerman, B.; Pearson, C.; Kaufman, G.; Chen, C.; Wang, G. Niu, T.; Wise, P.H.; Bauchner, $\mathrm{H}$; $\mathrm{Xu}, \mathrm{X}$. Maternal cigarette smoking. Metabolic gene polymorphism and infant birth weight. JAMA 2002, 287, 195-202.

18. Nebert, D.W.; Dalton, T.P. The role of cytochrome P450 enzymes in endogenous signaling pathways and environmental carcinogenesis. Nat. Rev. Cancer 2006, 6, 947-960.

19. Filho, M.B.; Albano, R.M.; Rossini, A.; Pinto, L.F.R. Pharmacogenomics of xenobiotic metabolizing enzymes in south American populations. Curr. Pharmacogen. 2006, 4, 9-18.

20. Bartsch, H.; Rojas, M.; Alexandrov, K.; Camus, A.M.; Castegnaro, M.; Malaveille, C. Anttila, S.; Hirvonen, K.; Husgafvel-Pursiainen, K.; Hietanen, E.; et al. Metabolic polymorphism affecting DNA binding and excretion of carcinogens in humans. Pharmacogenetics 1995, 5, 84-90.

21. Bartsch, H. DNA adducts in human carcinogenesis: etiological relevance and structure-activity relationship. Mutat. Res. 1996, 340, 67-79.

22. Kriek, E.; Rojas, M.; Alexandrov, K.; Bartsch, H. Polycyclic aromatic hydrocarbon-DNA adducts in humans: relevance as biomarkers for exposure and cancer risk. Mutat. Res. 1998, 400, 215-231.

23. Hayes, J.D.; Strange, R.C. Glutathione S-transferase polymorphisms and their biological consequences. Pharmacology 2000, 61, 154-166.

24. Hong, Y.C.; Lee, K.H.; Son, B.K.; Ha, E.H.; Moon, H.S.; Ha, M. Effects of the GSTM1 and GSTT1 polymorphisms on the relationship between maternal exposure to environmental tobacco smoke and neonatal birth weight. J. Occ. Environ. Med. 2003, 45, 492-498.

25. Infante-Rivard, C.; Weinberg, C.R.; Guiguet, M. Xenobiotic-metabolizing genes and small-forgestational-age births: interaction with maternal smoking. Epidemiology 2006, 17, 38-46. 
26. Park, E.Y.; Hong, Y.C.; Lee, K.H.; Im, M.W.; Ha, E.; Kim, Y.J.; Ha, M. Maternal exposure to environmental tobacco smoke, GSTM1/T1 polymorphism and oxidative stress. Reprod. Toxicol. 2008, 26, 197-202.

27. Nieuwenhuijsen, M.J.; Smith, R.; Golfinopoulos. S.; Best, N.; Bennett. J.; Aggazzotti. G.; Righi, E.; Fantuzzi, G.; Bucchini, L.; Cordier, S.; Villanueva, C.M.; Moreno, V.; La Vecchia, C.; Bosetti, C.; Vartiainen, T.; Rautiu, R.; Toledano, M.; Iszatt, N.; Grazuleviciene, R.; Kogevinas. M. Health impacts of long-term exposure to disinfection by-products in drinking water in Europe: HIWATE. J. Water Health 2009, 7, 185-207.

28. Arand, M.; Mühlbauer, R.; Hengstler, J.; Jäger, E.; Fuchs, J.; Winkler, L.; Oesch, F. A multiplex polymerase chain reaction protocol for the simultaneous analysis of the glutathione S-transferase GSTM1 and GSTT1 polymorphisms. Anal. Biochem. 1996, 236, 184-186.

29. Agresti, A.; Wackerly, D.; Boyett, J.M. Exact conditional tests for cross-classifications: approximation of attained significance levels. Psychometrika 1979, 44, 75-83.

30. Luke, B.; Brown, M.B. Elevated risks of pregnancy complications and adverse outcomes with increasing maternal age. Hum. Reprod. 2007, 22, 1264-1272.

31. Oberg, S.; Ge, D.; Cnattingius, S.; Svensson, A.; Treiber, F.A.; Snieder, H.; Iliadou, A. Ethnic differences in the association of birth weight and blood pressure. Am. J. Hypertens. 2007, 20, 1235-1241.

32. Sable, M.R.; Wilkinson, D.S. Impact of perceived stress, major life events and pregnancy attitudes on low birth weight. Fam. Plann. Perspect. 2000, 32, 288-294.

33. Savitz, D.A.; Dole, N.; Terry, J.W., Jr.; Zhou, H.; Thorp, J.M., Jr. Smoking and pregnancy outcome among African-American and white women in central North Carolina. Epidemiology 2001, 12, 636-642.

34. Nukui, T.; Day, R.D.; Sims, C.S.; Ness, R.B.; Romkes, M. Maternal/newborn GSTT1 null genotype contributes to risk of preterm, low birthweight infants. Pharmacogenetics 2004, 14, 569-576.

35. Sasaki, S.; Kondo, T.; Sata, F.; Saijo, Y.; Katoh, S.; Nakajima, S.; Ishizuka, M.; Fujita, S.; Kishi, R. Maternal smoking during pregnancy and genetic polymorphisms in the Ah receptor, CYP1A1 and GSTM1 affect infant birth size in Japanese subjects. Mol. Hum. Reprod. 2006, 12, 77-83.

36. Sram, R.J.; Binkova, B.; Dejmek, J.; Chvatalova, I.; Solansky, I.; Topinka, J. Association of NDA adducts and genotypes with birth weight. Mutat. Res. 2006, 608, 121-128.

37. Kishi, R.; Sata, F.; Yoshioka, E.; Ban, S.; Sasaki, S.; Konishi, K.; Washino, N. Exploiting geneenvironment interaction to detect adverse health effects of environmental chemicals on the next generation. Basic Clin. Pharmacol. Toxicol. 2008, 102, 191-203.

38. Tsai, H.J.; Liu, X.; Mestan, K.; Yu, Y.; Zhang, S.; Fang, Y.; Pearson, C.; Ortiz, K.; Zuckerman, B.; Bauchner, H.; Cerda, S.; Stubblefield, P.G.; Xu, X.; Wang, X. Maternal cigarette smoking, metabolic gene polymorphisms, and preterm delivery: new insights on GxE interactions and pathogenic pathways. Hum. Genet. 2008, 123, 359-369.

39. Givel, M.S.; Glantz, S.A. Failure to defend a successful state tobacco control program: policy lesson. Am. J. Public Health 2000, 90, 762-767. 
40. Rudatsikira, E.; Muula, A.S.; Siziya, S.; Mataya, R.H. Correlates of cigarette smoking among school-going adolescents in Thailand: findings from the Thai global youth tobacco survey 2005 . Int. Arch. Med. 2008, 1, 8; Published online 2008 June 11. doi: 10.1186/1755-7682-1-8.

(C) 2009 by the authors; licensee Molecular Diversity Preservation International, Basel, Switzerland. This article is an open-access article distributed under the terms and conditions of the Creative Commons Attribution license (http://creativecommons.org/licenses/by/3.0/). 